\title{
Standardization of a cytometric p24-capture bead-assay for the detection of main HIV-1 subtypes.
}

\author{
Mélanie Merbah $^{\mathrm{a}, \mathrm{b}}$, Sayali Onkar ${ }^{\mathrm{a}, \mathrm{b}}$, Jean-Charles Grivel ${ }^{\mathrm{c},{ }^{*}}$, Christophe Vanpouille ${ }^{\mathrm{c}}$, \\ Angélique Biancotto ${ }^{\mathrm{d}}$, Lydia Bonar ${ }^{\mathrm{a}, \mathrm{b}}$, Eric Sanders-Buell ${ }^{\mathrm{a}, \mathrm{b}}$, Gustavo Kijak ${ }^{\mathrm{a}, \mathrm{b}}$, Nelson \\ Michael $^{\mathrm{a}}$, Merlin Robb ${ }^{\mathrm{a}, \mathrm{b}}$, Jerome H. Kim ${ }^{\mathrm{a}, \mathrm{A}}$, Sodsai Tovanabutra ${ }^{\mathrm{a}, \mathrm{b}}$, Agnès-Laurence \\ Chenine $e^{\mathrm{a}, \mathrm{b}}$
}

${ }^{a}$ U.S. Military HIV Research Program, Walter Reed Army Institute of Research,

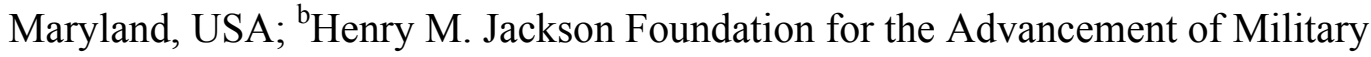
Medicine, Maryland, USA; ${ }^{\mathrm{c} E u n i c e}$ Kennedy Shriver National Institute of Child Health and Human Development, Program of Physical Biology, National Institutes of Health, Maryland, USA; ${ }^{\mathrm{d} C e n t e r}$ for Human Immunology, Autoimmunity, and Inflammation, National Institutes of Health, Bethesda, USA

E-mail addresses: mmerbah@hivresearch.org (M. Merbah), sonkar@hivresearch.org (S. Onkar), jgrivel@sidra.org (J-C. Grivel), vanpouic@mail.nih.gov (C. Vanpouille), biancoa@nhlbi.nih.gov (A. Biancotto), lbonar@hivresearch.org (L. Bonar), esandersbuell@hivresearch.org (E. Sanders-Buell),gkijak@hivresearch.org (G. Kijak), nmichael@hivresearch.org (N. Michael), mrobb@hivresearch.org (M. Robb), jerome.kim@ivi.int (J. H. Kim), stovanabutra@hivresearch.org (S. Tovanabutra), achenine@hivresearch.org (A-L. Chenine)

Corresponding author: Melanie Merbah, mmerbah@hivresearch.org

* Present address: Sidra Medical and Research Center, Doha, Qatar

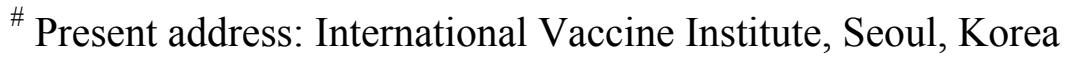

This work was supported by a cooperative agreement (W81XWH-11-2-0174) between the Henry M. Jackson Foundation for the Advancement of Military Medicine, Inc., and the U.S. Department of Defense (DoD). The views expressed are those of the authors and should not be construed to represent the positions of the United States Departments of the Army, Defense, or Health and Human Services. 


\begin{abstract}
The prevailing method to assess HIV-1 replication and infectivity is to measure the production of p24 Gag protein by enzyme-linked immunosorbent assay (ELISA). Since fluorescent bead-based technologies offer a broader dynamic range and higher sensitivity, this study describes a p24 capture Luminex assay capable of detecting HIV-1 subtypes A, B, C, D, circulating recombinant forms (CRF) CRF01_AE and CRF02_AG, which together are responsible for over 90\% of HIV1 infections worldwide. The success of the assay lies in the identification and selection of a cross-reactive capture antibody (clone 183-H12-5C). Fifty-six isolates that belonged to six HIV1 subtypes and CRFs were successfully detected with p-values below 0.021 ; limits of detection ranging from 3.7 to $3 \times 10^{4} \mathrm{pg} / \mathrm{ml}$. The intra- and inter-assay variation gave coefficient of variations below 6 and 14\%, respectively.

The 183-bead Luminex assay also displayed higher sensitivity of $91 \%$ and $98 \%$ compared to commercial p24 ELISA and a previously described Luminex assay. The p24 concentrations measured by the 183-bead Luminex assay showed a significant correlation $(R=0.92, p<0.0001)$ with the data obtained from quantitative real time PCR.

This newly developed p24 assay leverages the advantages of the Luminex platform, which include smaller sample volume and simultaneous detection of up to 500 analytes in a single sample, and delivers a valuable tool for the field.
\end{abstract}

\title{
Keywords:
}

HIV-1; p24; detection; multi-subtype; multiplex assay

Abbreviations: C-Ab: capture antibody; FI: fluorescence intensity; HIV-IG: mix of human HIV immunoglobulins derived from pooled plasma of asymptomatic HIV-positive donors; IGbeads: beads coated with capture HIV-IG; mAb: monoclonal antibody; 183-beads: beads coated with the anti-p24 capture monoclonal antibody clone 183-H12-5C; 39/5.4A-beads: beads coated with the anti-p24 capture monoclonal antibody clone 39/5.4A; 4F6-beads: beads coated with the anti-p24 capture monoclonal antibody clone 4F6. 


\section{Introduction}

HIV p24 Gag protein is a commonly used marker of HIV replication clinically and scientifically. Although monitoring HIV-1 replication in vitro can be carried out by quantification of viral nucleic acid, the most common method to assess replication and infectivity is to measure p24 production by Enzyme-Linked Immunosorbent Assay (ELISA) (Patton et al., 2006; Schupbach, 2003). p24 is the structural protein of the viral capsid whose highly conserved amino acid sequence (Coplan et al., 2005) and abundance (Summers et al., 1992; Vogt and Simon, 1999) make it an ideal candidate for HIV detection.

Commercially available p24 ELISAs are reliable, specific, sensitive and widely used in the field; however, drawbacks include a narrow dynamic range and high cost. Currently, fluorescent beadbased technologies, like Luminex, offer a broader dynamic range, higher sensitivity and lower cost (Biancotto et al., 2009). Additionally, the Luminex platform requires a smaller sample volume than the ELISA and permits the simultaneous detection of up to 500 analytes in a single sample. The ability to screen up to 1000 samples per day confers an added advantage to this technique. The core technology is based on microspheres internally dyed with fluorophores that are pre-coated with antibodies to capture analytes of interest (C-Ab; capture antibody). Detection of the bound antibody-protein complex is based on the photometric reading of the laser-excited fluorescent detection antibody that sandwiches the captured antigen. As for all immunological assays, the success relies on the avidity and specificity of the C-Abs selected. Biancotto et al. (Biancotto et al., 2009) developed a sensitive assay for the detection of p24 using the Luminex technology that has been used in many HIV-1 subtype B studies (Balzarini et al., 2013; Introini et al., 2013; Merbah et al., 2012; Parrish et al., 2013; Saba et al., 2010; Vanpouille et al., 2012). However, the C-Ab described by Biancotto et al. lacks sensitivity for some HIV-1 non-B subtypes which account for almost $90 \%$ of HIV-1 infections worldwide (Hemelaar et al., 2011). Hence, having an assay that allows the assessment of virus production regardless of the subtype is important.

Here we present the development of a Luminex based assay using a p24 capture monoclonal antibody ( $\mathrm{mAb}$ ), that detects $\mathrm{B}$ and non-B subtypes. Assay performance was evaluated on a panel of 56 HIV-1 isolates representing subtypes A, B, C, D, CRF01_AE and CRF02_AG, by comparing p24 concentrations measured with the Luminex assay developed by Biancotto et al. 
(Biancotto et al., 2009) and a commercially available p24 ELISA kit (Tang et al., 2010).

Additionally, the performance of the assay was compared with real-time quantitative Polymerase Chain Reaction (qPCR) (Schupbach, 2003; Stefan et al., 2003).

\section{Materials and Methods}

\subsection{HIV-1 isolates}

The 56 virus isolates (Table 1) belong to the International Panel of HIV-1 Isolates (Brown et al., 2005) representing the six major globally prevalent strains A, B, C, D, CRF01_AE and CRF02_AG. Available through the NIH AIDS Reagent Program (Cat \#11412), they constitute a resource for standardization for studies using different HIV-1 subtypes and are wildly used (Jones et al., 2012; Rosa Borges et al., 2010; Stoddart et al., 2015; Zhai et al., 2013). To ensure consistency of our measurement over time, a $500 \mu 1$ or $1 \mathrm{ml}$ vial of virus stock was thawed, divided into $100 \mu 1$ aliquots and stored at $-80^{\circ} \mathrm{C}$.

\section{2. p24 quantification by ELISA}

To measure the p24 concentration of the isolates, a commercial p24 capture ELISA kit (Advance Bioscience Laboratories, Rockville, MD, USA) was used per the manufacturers' instruction. A modified version of this ELISA was also used to test the binding abilities of the $\mathrm{C}$-Ab candidates (Table 2) to the p24 of the different HIV-1 subtypes. The wells of a flat-bottom polystyrene 96well plate (Thermo Scientific, Boston, MA, USA) were coated with $100 \mu 1$ of bicarbonate buffer $\left(15 \mathrm{mM} \mathrm{Na}_{2} \mathrm{CO}_{3}\right.$ and $\left.35 \mathrm{mM} \mathrm{NaHCO}_{3}, \mathrm{pH} 9.6\right)$ containing $4 \mu \mathrm{g} / \mathrm{ml}$ of capture-antibody, and incubated overnight at $4^{\circ} \mathrm{C}$. The coating solution was then removed and other protein binding sites were blocked by adding $250 \mu 1$ per well of a blocking solution (1X PBS, $0.5 \%$ skim milk powder and $0.1 \%$ Tween $20, \mathrm{pH} 7.4$ ), and incubated at room temperature (RT) for 2 hours. After the blocking solution was removed, the assay was completed by using the commercial reagents from the p24 capture ELISA cited above and following the instruction of the manufacturer.

\subsection{Beads coupling reaction and validation}


The C-Ab yielding the best result was selected for coupling to beads. The content of a vial of carboxylated magnetic beads region $43\left(1.25 \times 10^{7}\right.$ beads, $1 \mathrm{ml}$, region $43,6.5 \mu \mathrm{m}$ in diameter, Luminex Corp. Austin, TX, USA) was transferred into a low binding microcentrifuge tube (Eppendorf, Hamburg, Germany) and centrifuged at $8000 \mathrm{x}$ g for 2 minutes. After a wash in $200 \mu \mathrm{l}$ of $\mathrm{H}_{2} \mathrm{O}$, the beads were pelleted, resuspended in $160 \mu \mathrm{l}$ of $100 \mathrm{mM} \mathrm{NaH}_{2} \mathrm{PO}_{4}$ (SigmaAldrich, St. Louis, MO, USA) pH 6.2 and activated for 20 minutes under agitation by adding $20 \mu \mathrm{l}$ of $50 \mathrm{mg} / \mathrm{ml}$ of Sulfo-NHS (sulfo-N-hydroxysuccinimide) (Pierce Biotechnoloy Inc., Rockford, IL, USA) and $20 \mu 1$ of $50 \mathrm{mg} / \mathrm{ml}$ of EDC (1-ethyl-3-[3-dimethylaminopropyl] carbodiimide hydrochloride) (Pierece Biotechnoloy Inc). The solution of Sulfo-NHS and EDC were freshly prepared and checked for the correct $\mathrm{pH}$ before each coupling procedure. The activated beads were washed twice in $250 \mu 1$ of $100 \mathrm{M}$ of MES (2[N-Morpholino] ethanesulfonic acid) (Fisher Scientific, Pittsburgh, PA, USA) solution pH 6, centrifuged and resuspended in $250 \mu \mathrm{l}$ of $100 \mathrm{M}$ of MES. $110 \mu \mathrm{g}$ of C-Ab diluted in PBS were added and the total volume brought to $1 \mathrm{ml}$ with $100 \mathrm{mM}$ MES pH6. The coupling reaction proceeded for 2 hours at RT with a gently stirring at $4{ }^{\circ} \mathrm{C}$ overnight. The coupled beads were then centrifuged, resuspended and incubated under constant stirring at RT for 30 minutes in $500 \mu 1$ of PBS-TBN (1X PBS, $0.1 \%$ BSA, $0.02 \%$ Tween 20 and $0.05 \%$ Sodium Azide). After two washes with $500 \mu 1$ of PBS-TBN, the coupled beads were finally resuspended in $1 \mathrm{ml}$ of PBS-TBN. The bead concentration was determined with a hemocytometer, and the $\mathrm{C}$-Ab-beads were stored at $4^{\circ} \mathrm{C}$ in the dark. During the coupling procedure, the beads were protected from the light as much as possible. All centrifugation steps were performed at $\geq 8000 \mathrm{x}$ g for 2 minutes. After each wash the beads were vortexed at maximum speed for 30 seconds and sonicated for 15 seconds.

The coupling procedure was then validated by incubating the protein-coupled beads with serially diluted PE-labeled antibody solutions, ranging from $6.25 \mu \mathrm{g} / \mathrm{ml}$ to $200 \mu \mathrm{g} / \mathrm{ml}$ for 1 hour. The beads were then washed and resuspended in $200 \mu 1$ of BD FACSFlow ${ }^{\text {TM }}$ (BD Biosciences, San Diego, CA, USA) and acquired on a LSRII flow cytometer (BD Biosciences, San Diego, CA, USA) using DIVA software version 8.0.1 (BD Biosciences, San Diego, CA, USA), and analyzed with FlowJo version 9.8.2 (Tree Star, Ashland, OR). 


\section{4. p24 Luminex capture assay}

The p24 Luminex capture assay was performed in a flat bottom 96-well plate. The washes were performed using an automatic magnetic washer; and the plates were kept from the light during incubation. The magnetic beads were diluted in the assay buffer $(20 \mathrm{mM}$ Tris Hcl pH6, 0.1\% BSA and $0.05 \%$ Tween 20 ) to a concentration of 60,000 beads $/ \mathrm{ml}$ and $50 \mu \mathrm{l}$ (3000 beads) were added in each well. The samples and the p24 standards were lysed by adding a $10 \%$ volume of a 10X lysis solution (10X Triton X-100 and $0.05 \%$ Tween 20 ) for 1 hour at $37^{\circ} \mathrm{C}$, and then diluted in assay buffer. $50 \mu 1$ of the lysed samples or standard were added to the magnetic beads and incubated for 1 hour at RT under agitation. The plates were then washed twice with $200 \mu 1$ of a wash solution (20mM Tris Hcl pH6 and 0.05\% Tween 20) using a magnetic microplate washer (ELx405, BioTek, Winooski, VT, USA). 100 $\mu$ l of the detection antibody anti-p24 KC57 (Beckman Coulter, Fullerton, CA, USA) was added to each well, and the plates were incubated for 1 hour at RT under agitation. The plates were washed twice with $200 \mu$ of a wash solution. The magnetic beads were resuspended in $100 \mu$ of assay buffer and agitated for 10 minutes before the analysis. The analysis of the magnetic beads was done on a Luminex 100 using the Bioplex manager software version 6.0 (Bio-Rad, Hercules, CA) and a minimum of 300 beads per well were analyzed.

\subsection{Quantitative PCR for HIV-1 Gag RNA}

The quantification of HIV-1 Gag by quantitative PCR was performed by extracting HIV-1 RNA from the viral stocks using the QIAamp viral RNA mini kit (QIAGEN Gmbh, Hilden, Germany) per the manufacturer's instruction. The viral RNA was reverse transcribed to complementary DNA synthesis (cDNA) using the SuperScript III RT kit (Invitrogen, Carlsbad, CA, USA) following the manufacturer's instructions and 5'Primer (5'-AGT TCT TCT GAT CCT GT-3'). Number of gag cDNA copies was quantified against dilutions of cells engineered to express only 1 copy of HIV gag DNA (8E5 cell line) per cell using 7500 Real Time PCR System (Applied Biosystems, Foster City, CA, USA). Briefly, duplicate PCR reactions at a final volume of 12.5 $\mu 1$ containing $1.25 \mu \mathrm{l}$ of $10 \mathrm{X}$ PCR buffer, $200 \mu \mathrm{M}$ dNTP, 3.5mM MgCl2, $800 \mathrm{nM}$ of primers (Forward primer 5'-TGA CTA GCG GAG GCT AGA A-3', Reverse primer 5'-CTC YCT GCT 
TGCCCA TA-3'), 1.25 U of Platinum Taq DNA Polymerase (Invitrogen Carlsbad, CA, USA), and $2 \mu \mathrm{l}$ of cDNA was subjected to pre-amplification using an MJ Research PTC-225 thermal cycler (Bio-Rad Laboratories, Hercules, CA, USA). The cycling condition was $94^{\circ}$ for 2 min followed by 12 cycles of $95^{\circ}$ for $30 \mathrm{sec}$ and $60^{\circ}$ for $1 \mathrm{~min}$. A $2 \mu \mathrm{l}$ aliquot of each preamplification products was subjected to a Taqman real-time PCR and a reaction mixture contained 1.25 $\mu \mathrm{l}$ of 10X PCR buffer, $200 \mu \mathrm{M}$ dNTP, $3.5 \mathrm{mM}, \mathrm{MgCl} 2,800 \mathrm{nM}$ of primers, $2.5 \mathrm{U}$ of Platinum taq (Invitrogen Carlsbad, CA), $0.375 \mu$ l of ROX reference dye (Invitrogen Carlsbad, CA, USA) and $0.2 \mathrm{pM}$ of probe (5'-[6FAM] AAA ATT CGG TTA AGS CCA GGG GGA AAG AA[BHQ1]-3'). The cycling condition was $94^{\circ}$ for 2 min followed by 45 cycles of $95^{\circ}$ for $30 \mathrm{sec}$ and $60^{\circ}$ for $1 \mathrm{~min}$ and performed using a 7900HT Fast Real Time PCR System (Applied Biosystems, Foster City, CA, USA).

\subsection{Statistical analysis}

The statistical analyses were done using GraphPad Prism 6. Statistical significance was evaluated with a one sample t-test (with theoretical mean $=0$ ) or multiple $t$-tests. The correlation coefficient between HIV-1 RNA copy number and p24 antigen concentration was evaluated using the non-parametric Pearson correlation.

\section{Results}

\subsection{Identification and validation of cross-reactive p24 C-Abs}

Two mAb directed towards HIV-1 p24, 183-H12-5C and 39/5.4A were selected based on their reported ability to react with non-B HIV-1 subtypes (Table 2) (Chauveau et al., 2015; Huang et al., 2014); a third candidate, a mix of human HIV immunoglobulins (HIV-IG) (NIH AIDS Reagent Program) was also added. In preliminary ELISA tests, all three C-Ab were able to detect the protein of six subtypes (A, B, C, D and CRF01_AE and CRF02_AG) isolates (data not shown).

The three candidates were further evaluated on the Luminex platform. Capture beads were generated using the mAb 183-H12-5C (183-beads) and 39/5.4A (39/5.4A-beads), and the HIV- 
IG (IG-beads). The clone 4F6 (4F6-beads), previously used by Biancotto et al. (Biancotto et al., 2009), served as a control. The efficiency of the coupling reactions was validated by mixing the coupled microspheres with dilutions of a phycoerythrin (PE)-labeled anti-species IgG detection antibody (ranges from $6.25-200 \mu \mathrm{g} / \mathrm{ml}$ ) and assessed by flow cytometry. The intensity of the fluorescent signal was proportional to the amount of detection antibody on the surface of the beads (Figure 1), indicating that all coupling procedures were successful. The functionality of the capture beads was further assessed by mixing them with serial dilutions of purified p24 protein. The fluorescence read by the Luminex is shown in Figure 2. The fluorescence intensity (FI) of the 183-beads showed a dose-dependent response comparable to the 4F6-beads. The 39/5.4Aand IG-beads failure to respond in a dose dependent manner indicated that they did not bind to the protein, or that their binding prevented the binding of the detection antibody. The clone 183$\mathrm{H} 12-5 \mathrm{C}$ was the only $\mathrm{C}-\mathrm{Ab}$ that met the criteria for further development.

\subsection{Performances of the HIV-1 p24 capture Luminex assay - using an international panel of} $H I V-1$ isolates

The p24 capture Luminex assay using the 183-beads (183-beads Luminex) was performed on a panel of HIV-1 isolates (Brown et al., 2005) representing 6 major subtypes and recombinant forms (A, B, C, D, CRF01_AE and CRF02_AG). Out of 60 isolates from the panel, 56 were available for quantification (Table 1). To determine the p24 concentrations, a p24 standard curve (Figure 3) was run in quadruplicate and fitted by a logistic 5-parameter regression $\left(\mathrm{R}^{2}=0.9993\right.$, $\mathrm{EC}=17,528 \mathrm{pg} / \mathrm{ml}$, Hill slope $=1.14$ ). The broad dynamic range of the assay and its reproducibility are shown in Figure 3; the intra-assay variation of the quadruplicates and interassay of four different experiments gave coefficients of variation (CVs) below 6 and 14\% respectively. The range of detection ran from $3.7 \mathrm{pg} / \mathrm{ml}$ to $30,000 \mathrm{pg} / \mathrm{ml}$. The quantification of the HIV-1 isolates presented in Figure 4 demonstrates that, with no exception, the 56 isolates were detected by the assay (p-value range: $<0.0001-0.0208$, one sample t-test) with p24 concentrations ranging from $3.2 \times 10^{2}$ to $5.1 \times 10^{6} \mathrm{pg} / \mathrm{ml}$. The CVs of the samples, run in quadruplicates, were between 0.92 and $29.57 \%$. 
To assess the inter-assay variation, three additional independent experiments were carried out in duplicate on 30 isolates over a period of six months. The four experiments are represented in Figure 5; the CVs measured were between 14.31 and $34.46 \%(n=10)$.

\subsection{Validation against established HIV-1 quantification methods}

The newly developed 183-bead Luminex assay was further compared to three different HIV-1 quantification methods: a commercial p24 ELISA kit, broadly used in the field (Humeau et al., 2004; Kuroishi et al., 2009); the p24 capture assay described by Biancotto et al. (Biancotto et al., 2009) (using the 4F6-beads Luminex); and quantification of viral nucleic acid by qPCR. The p24 ELISA kit was used to evaluate the p24 concentration of the 56 isolates. As shown in Figure 6 by the shift observed along the x-axis, the 183-bead Luminex was more sensitive for 51 isolates: the concentrations ranged from 1.3- to 11.9-fold higher than the concentrations measured with the ELISA kit. With the caveat that the ELISA assay was more sensitive with subtype A viruses, exceptions were found for 5 isolates (Figure 6, empty circle): subtype A (A-) 00KE_KER2018, A-00KE_KNH1209, A-00KE_KSM4030, A-99KE_KNH1135 and AG01CM_0008BBY; although a higher sensitivity was observed with the ELISA for these isolates, they were still detected by the 183-bead Luminex assay (Figure 4). In addition, twelve isolates from the panel were tested with the 4F6-bead Luminex assay as well (Figure 7 and Table 3). Since mAb 4F6 was isolated from a subtype B patient (company data sheet), the detection of p24 for subtypes B and D (B-90TH_BK132, B-90US_873, D-00KE_NKU3006 and D99UG_A03349M1) was found more sensitive and the concentration significantly higher with the 4F6-beads Luminex compared to the ELISA kit ( $<<0.0001$ ). However, the concentrations measured for the other non-B isolates using the 4F6-beads Luminex assay were significantly lower than the concentration measured by the commercial ELISA kit $(\mathrm{p}<0.0025)$ (Table 3). A direct comparison of both Luminex assays (Figure 7 and Table 3) showed that the detection of p24 was more sensitive and the concentration significantly higher $(\mathrm{p}<0.0001)$ when using the 183-beads for all isolates tested except for one (D-00KE_NKU3006) for which the concentration was similar $(\mathrm{p}=0.034)$.

Finally, 30 isolates were quantified by quantitative PCR as a standard method to monitor in vitro HIV-1 replication (Schupbach, 2003; Stefan et al., 2003) and compared to the 183-beads 
Luminex assay a significant correlation of HIV-1 RNA and $\mathrm{p} 24$ antigen was found $(\mathrm{R}=0.92$, $\mathrm{p}<0.0001)$.

\section{Discussion}

The assay developed by Biancotto et al. (Biancotto et al., 2009) using mAb 4F6 as a C-Ab has demonstrated a great ability to measure concentrations of HIV-1 belonging to B subtypes (Balzarini et al., 2013; Introini et al., 2013; Merbah et al., 2012; Parrish et al., 2013; Saba et al., 2010; Vanpouille et al., 2012); however, its capacity to measure p24 from multiple non-B samples was more limited and opened the door for an assay using a more universal C-Ab. Biancotto et al. have established the multiple benefits of using a p24 capture Luminex assay: lower cost, a broad dynamic range, and high sensitivity. Additionally, the multitasking flow cytometry platform provides also an opportunity to multiplex with up to 499 additional analytes using $50 \mu 1$ of sample. A major obstacle in developing a universal HIV-1 p24 Luminex assay lies in the fact that a majority of available anti-p24 mAbs were isolated from patients infected with HIV-1 subtype B. In this study, the limitation of using subtype B-derived antibodies was mitigated by screening the literature for cross-reactive antibodies available in the public domain. The three Abs selected here were evaluated for multi-subtype detection. All three Abs (two mAbs (clones 39/5.4A and 183-H12-5C) and HIV-IG) were able to detect p24 from subtypes A, B, C, D and CRF01_AE and CRF02_AG by ELISA, but only the clone 183-H12-5C was able to bind p 24 protein using the Luminex assay. One possible explanation for the differences observed in binding affinity is the change of antibody structure after coupling to the beads. This coupling procedure is achieved via carbodiimide reactions involving the primary amino groups on the antibodies, located on lysine residues and the $\mathrm{N}$-terminus of each polypeptide chain, and the carboxyl functional groups on the bead surface. Therefore, the orientation of the antibody as well as the availability of the antigen-binding site cannot be controlled during the coupling procedure. This could explain why these antibodies did not detect p24 once coupled to the beads. The p24 Luminex capture assay using the clone $183-\mathrm{H} 12-5 \mathrm{C}$ was able to detect and measure the p24 concentration of the 56 isolates from the international HIV-1 panel (Brown et al., 2005) representing subtypes A, B, C, D, CRF01_AE and CRF02_AG. In a direct comparison, 91\% of the isolates tested with the Luminex capture assay outperformed the commercial p24 ELISA kit; 
reduced sensitivity was observed in four out of nine subtype A, and one out of ten CRF02_AG isolates. The gag gene coding for p24 of CRF02_AG belongs to HIV-1 subtype A that is the most diverse among HIV-1 subtypes. Hence, it is possible that 183-H12-5C which was subtype B derived antibody does not fully bind to all of the subtype A lineages. The variations within the gag gene and consequently within p24 from different clades explain the difference in sensitivity Furthermore, the 183 bead p24 Luminex capture assay successfully detected HIV-1 p24 antigen from viral stocks, the supernatants of cultured, HIV-infected cells (cell lines, PBMCs, macrophages) as well as supernatant from CRF01_AE infected human tissue explants which requires a highly sensitive assay due to the low level of viral replication. The sensitivity of this assay may be improved in the future by decreasing the number of beads per well as shown by Biancotto et al. (Biancotto et al., 2009).

The focus of much of the world's vaccine studies and HIV-1 research is located in areas where non-B subtypes are prevalent. It is crucial to generate assays that combine low cost and broad reactivity across subtypes. With the added benefit of multiplexing, and conservation of sample, the p24 Luminex capture assay presented here offers a valuable and timely new tool for the field. 


\section{Acknowledgement}

We are thankful to Victoria Polonis for providing us with the $56 \mathrm{HIV}-1$ isolates.

We also want to thank Mangala Rao for the participation of her team in performing the p24 ELISA.

HIV-1 p24 Monoclonal Antibody (183-H12-5C): The following reagent was obtained through the NIH AIDS Reagent Program, Division of AIDS, NIAID, NIH: HIV-1 p24 Monoclonal Antibody (183-H12-5C) from Dr. Bruce Chesebro and Kathy Wehrly. HIV Immunoglobulin (HIV-IG): The following reagent was obtained through the NIH AIDS

Reagent Program, Division of AIDS, NIAID, NIH: Catalog \#3957, HIV-IG from NABI and NHLBI 


\section{References}

Balzarini, J., Andrei, G., Balestra, E., Huskens, D., Vanpouille, C., Introini, A., Zicari, S., Liekens, S., Snoeck, R., Holy, A., Perno, C.F., Margolis, L. and Schols, D., 2013. A multi-targeted drug candidate with dual anti-HIV and anti-HSV activity. PLoS Pathog 9, e1003456.

Biancotto, A., Brichacek, B., Chen, S.S., Fitzgerald, W., Lisco, A., Vanpouille, C., Margolis, L. and Grivel, J.-C.C., 2009. A highly sensitive and dynamic immunofluorescent cytometric bead assay for the detection of HIV-1 p24. Journal of virological methods $157,98-101$.

Brown, B.K., Darden, J.M., Tovanabutra, S., Oblander, T., Frost, J., Sanders-Buell, E., Souza, M.S.d., Birx, D.L., McCutchan, F.E. and Polonis, V.R., 2005. Biologic and Genetic Characterization of a Panel of 60 Human Immunodeficiency Virus Type 1 Isolates, Representing Clades A, B, C, D, CRF01_AE, and CRF02_AG, for the Development and Assessment of Candidate Vaccines. Journal of Virology 79, 6089-6101.

Chauveau, L., Puigdomenech, I., Ayinde, D., Roesch, F., Porrot, F., Bruni, D., Visseaux, B., Descamps, D. and Schwartz, O., 2015. HIV-2 infects resting CD4+ T cells but not monocyte-derived dendritic cells. Retrovirology 12, 2.

Coplan, P.M., Gupta, S.B., Dubey, S.A., Pitisuttithum, P., Nikas, A., Mbewe, B., Vardas, E., Schechter, M., Kallas, E.G., Freed, D.C., Fu, T.-M.M., Mast, C.T., Puthavathana, P., Kublin, J., Brown Collins, K., Chisi, J., Pendame, R., Thaler, S.J., Gray, G., McIntyre, J., Straus, W.L., Condra, J.H., Mehrotra, D.V., Guess, H.A., Emini, E.A. and Shiver, J.W., 2005. Cross-reactivity of anti-HIV-1 T cell immune responses among the major HIV-1 clades in HIV-1-positive individuals from 4 continents. The Journal of infectious diseases 191, 1427-1434.

Hemelaar, J., Gouws, E., Ghys, P.D., Osmanov, S., Isolation, W.-U.N.f.H. and Characterisation, 2011. Global trends in molecular epidemiology of HIV-1 during 2000-2007. AIDS (London, England) 25, 679-689.

Huang, S.W., Wang, S.F., Lin, Y.T., Yen, C.H., Lee, C.H., Wong, W.W., Tsai, H.C., Yang, C.J., Hu, B.S., Lin, Y.H., Wang, C.T., Wang, J.J., Hu, Z., Kuritzkes, D.R., Chen, Y.H. and Chen, Y.M., 2014. Patients infected with CRF07_BC have significantly lower viral loads than patients with HIV-1 subtype B: mechanism and impact on disease progression. PLoS One 9, e114441.

Humeau, L.M., Binder, G.K., Lu, X., Slepushkin, V., Merling, R., Echeagaray, P., Pereira, M., Slepushkina, T., Barnett, S., Dropulic, L.K., Carroll, R., Levine, B.L., June, C.H. and Dropulic, B., 2004. Efficient lentiviral vector-mediated control of HIV-1 replication in CD4 lymphocytes from diverse $\mathrm{HIV}+$ infected patients grouped according to CD4 count and viral load. Mol Ther 9, 902-13.

Introini, A., Vanpouille, C., Lisco, A., Grivel, J.C. and Margolis, L., 2013. Interleukin-7 facilitates HIV-1 transmission to cervico-vaginal tissue ex vivo. PLoS Pathog 9, e1003148.

Jones, R.B., Garrison, K.E., Mujib, S., Mihajlovic, V., Aidarus, N., Hunter, D.V., Martin, E., John, V.M., Zhan, W., Faruk, N.F., Gyenes, G., Sheppard, N.C., PriumboomBrees, I.M., Goodwin, D.A., Chen, L., Rieger, M., Muscat-King, S., Loudon, 
P.T., Stanley, C., Holditch, S.J., Wong, J.C., Clayton, K., Duan, E., Song, H., Xu, Y., SenGupta, D., Tandon, R., Sacha, J.B., Brockman, M.A., Benko, E., Kovacs, C., Nixon, D.F. and Ostrowski, M.A., 2012. HERV-K-specific T cells eliminate diverse HIV-1/2 and SIV primary isolates. The Journal of clinical investigation 122, 4473-4489.

Kuroishi, A., Saito, A., Shingai, Y., Shioda, T., Nomaguchi, M., Adachi, A., Akari, H. and Nakayama, E.E., 2009. Modification of a loop sequence between alphahelices 6 and 7 of virus capsid (CA) protein in a human immunodeficiency virus type 1 (HIV-1) derivative that has simian immunodeficiency virus (SIVmac239) vif and CA alpha-helices 4 and 5 loop improves replication in cynomolgus monkey cells. Retrovirology 6, 70.

Merbah, M., Arakelyan, A., Edmonds, T., Ochsenbauer, C., Kappes, J.C., Shattock, R.J., Grivel, J.-C.C. and Margolis, L.B., 2012. HIV-1 expressing the envelopes of transmitted/founder or control/reference viruses have similar infection patterns of CD4 T-cells in human cervical tissue ex vivo. PloS one 7.

Parrish, N.F., Gao, F., Li, H., Giorgi, E.E., Barbian, H.J., Parrish, E.H., Zajic, L., Iyer, S.S., Decker, J.M., Kumar, A., Hora, B., Berg, A., Cai, F., Hopper, J., Denny, T.N., Ding, H., Ochsenbauer, C., Kappes, J.C., Galimidi, R.P., West, A.P., Jr., Bjorkman, P.J., Wilen, C.B., Doms, R.W., O'Brien, M., Bhardwaj, N., Borrow, P., Haynes, B.F., Muldoon, M., Theiler, J.P., Korber, B., Shaw, G.M. and Hahn, B.H., 2013. Phenotypic properties of transmitted founder HIV-1. Proc Natl Acad Sci U S A 110, 6626-33.

Patton, J.C., Sherman, G.G., Coovadia, A.H., Stevens, W.S. and Meyers, T.M., 2006. Ultrasensitive Human Immunodeficiency Virus Type 1 p24 Antigen Assay Modified for Use on Dried Whole-Blood Spots as a Reliable, Affordable Test for Infant Diagnosis. Clinical and Vaccine Immunology 13, 152155.

Rosa Borges, A., Wieczorek, L., Johnson, B., Benesi, A.J., Brown, B.K., Kensinger, R.D., Krebs, F.C., Wigdahl, B., Blumenthal, R., Puri, A., McCutchan, F.E., Birx, D.L., Polonis, V.R. and Schengrund, C.-L.L., 2010. Multivalent dendrimeric compounds containing carbohydrates expressed on immune cells inhibit infection by primary isolates of HIV-1. Virology 408, 80-88.

Saba, E., Grivel, J.C., Vanpouille, C., Brichacek, B., Fitzgerald, W., Margolis, L. and Lisco, A., 2010. HIV-1 sexual transmission: early events of HIV-1 infection of human cervico-vaginal tissue in an optimized ex vivo model. Mucosal Immunol $3,280-90$.

Schupbach, J., 2003. Viral RNA and p24 Antigen as Markers of HIV Disease and Antiretroviral Treatment Success. International Archives of Allergy and Immunology 132, 196-209.

Stefan, A.K., Susanne, K., Brigitte, R., Christian, K., Martine, P., Oliver, G.O., Dieter, H. and Willi, K.R., 2003. Comparison of TaqMan ${ }^{\mathrm{TM}}$ real-time PCR and p24 Elisa for quantification of in vitro HIV-1 replication. Journal of Virological Methods 107, $169-175$.

Stoddart, C.A., Galkina, S.A., Joshi, P., Kosikova, G., Moreno, M.E., Rivera, J.M., Sloan, B., Reeve, A.B., Sarafianos, S.G., Murphey-Corb, M. and Parniak, M.A., 2015. Oral administration of the nucleoside EFdA (4'-ethynyl-2-fluoro-2'deoxyadenosine) provides rapid suppression of HIV viremia in humanized mice 
and favorable pharmacokinetic properties in mice and the rhesus macaque. Antimicrobial agents and chemotherapy 59, 4190-4198.

Summers, M.F., Henderson, L.E., Chance, M.R., Bess, J.W., South, T.L., Blake, P.R., Sagi, I., Perez-Alvarado, G., Sowder, R.C. and Hare, D.R., 1992. Nucleocapsid zinc fingers detected in retroviruses: EXAFS studies of intact viruses and the solution-state structure of the nucleocapsid protein from HIV-1. Protein science : a publication of the Protein Society 1, 563-574.

Tang, S., Zhao, J., Wang, A., Viswanath, R., Harma, H., Little, R.F., Yarchoan, R., Stramer, S.L., Nyambi, P.N., Lee, S., Wood, O., Wong, E.Y., Wang, X. and Hewlett, I.K., 2010. Characterization of immune responses to capsid protein p24 of human immunodeficiency virus type 1 and implications for detection. Clinical and vaccine immunology : CVI 17, 1244-1251.

Vanpouille, C., Lisco, A., Introini, A., Grivel, J.-C.C., Munawwar, A., Merbah, M., Schinazi, R.F., Derudas, M., McGuigan, C., Balzarini, J. and Margolis, L., 2012. Exploiting the anti-HIV-1 activity of acyclovir: suppression of primary and drugresistant HIV isolates and potentiation of the activity by ribavirin. Antimicrobial agents and chemotherapy 56, 2604-2611.

Vogt, V.M. and Simon, M.N., 1999. Mass determination of rous sarcoma virus virions by scanning transmission electron microscopy. Journal of virology 73, 7050-7055.

Zhai, Y., Zhong, Z., Zariffard, M., Spear, G.T. and Qiao, L., 2013. Bovine papillomavirus-like particles presenting conserved epitopes from membraneproximal external region of HIV-1 gp41 induced mucosal and systemic antibodies. Vaccine 31, 5422-5429. 
Table 1: List of the 56 isolates belonging to the 6 different subtypes.

\begin{tabular}{|c|c|c|c|c|c|}
\hline$\varangle$ & $\begin{array}{l}\text { 00KE_KER2008 } \\
\text { 00KE_KER2018 } \\
\text { 00KE_KNH1144 } \\
\text { 00KE_KNH1207 } \\
\text { 00KE_KNH1209 } \\
\text { 00KE_KSM4030 } \\
\text { 92UG_029 } \\
\text { 99KE_KNH1088 } \\
\text { 99KE_KNH1135 }\end{array}$ & $U$ & $\begin{array}{l}\text { 00TZ_A125 } \\
\text { 00TZ_A246 } \\
\text { 02ET_14 } \\
\text { 02ET_288 } \\
\text { 89SM_145 } \\
\text { 90SE_364 } \\
\text { 93MW_965 } \\
\text { 94IN_20635-4 } \\
\text { 98US_MSC5016 }\end{array}$ & 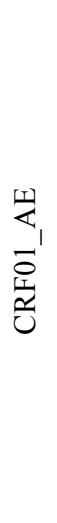 & $\begin{array}{l}\text { 90TH_CM235 } \\
\text { 90TH_CM240 } \\
\text { 90TH_CM244 } \\
\text { 96TH_M02138 } \\
\text { 96TH_NI1046 } \\
\text { 96TH_NI1149 } \\
\text { 97TH_NP1525 } \\
\text { 97TH_NP1695 } \\
\text { 98TH_NP1251 } \\
\text { 99TH_NI1052 }\end{array}$ \\
\hline . & $\begin{array}{l}\text { 84US_MNp } \\
\text { 85US_Ba-L } \\
\text { 89BZ_167 } \\
\text { 90TH_BK132 } \\
\text { 90US_873 } \\
\text { 91US-1 } \\
\text { 91US-4 } \\
\text { 92FR_BX08 } \\
\text { 94US_33931N } \\
\text { 96TH_NP1538 }\end{array}$ & D & $\begin{array}{l}\text { 00KE_NKU3006 } \\
\text { 00UG_E08364M4 } \\
\text { 00UG_E13613M4 } \\
\text { 93UG_065 } \\
\text { 98UG_57128 } \\
\text { 99UG_A03349M1 } \\
\text { 99UG_A07412M1 } \\
\text { 99UG_A08483M1 }\end{array}$ & 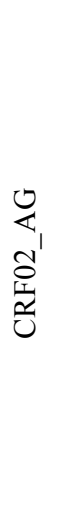 & $\begin{array}{l}\text { 01CM_0005BBY } \\
\text { 01CM_0008BBY } \\
\text { 01CM_1475MV } \\
\text { 01CM_CAM0002BBY } \\
\text { 02CM_0013BBY } \\
\text { 02CM_0014BBY } \\
\text { 02CM_0015BBY } \\
\text { 02CM_1970LE } \\
\text { 91DJ_263 } \\
\text { 98US_MSC5007 }\end{array}$ \\
\hline
\end{tabular}


Table 2: Capture antibodies references and description.

\begin{tabular}{|c|c|c|}
\hline Capture antibodies & $\begin{array}{l}\text { Manufacturer and catalog } \\
\text { number }\end{array}$ & $\underline{\text { Description }}$ \\
\hline $\begin{array}{l}\mathrm{mAb} \text { anti-p24 clone } \\
4 \mathrm{~F} 6\end{array}$ & $\begin{array}{l}\text { ImmunoDX, Woburn, MA, USA } \\
\text { Catalog \#1103 }\end{array}$ & $\begin{array}{l}\text { Mouse IgG monoclonal antibody to a linear epitope } \\
\text { (manufacturer's communication) of HIV-1 p24; } \\
\text { cross-reactivity with HIV-1 subtypes B, C and E } \\
\text { (manufacturer's communication). }\end{array}$ \\
\hline $\begin{array}{l}\mathrm{mAb} \text { anti-p24 clone } \\
183-\mathrm{H} 12-5 \mathrm{C}\end{array}$ & $\begin{array}{l}\text { NIH AIDS Reagent Program, } \\
\text { Bethesda, MD, USA } \\
\text { Catalog } \# 3537\end{array}$ & 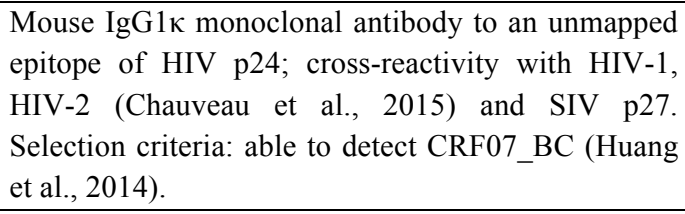 \\
\hline $\begin{array}{l}\mathrm{mAb} \text { anti-p24 clone } \\
39 / 5.4 \mathrm{~A}\end{array}$ & $\begin{array}{l}\text { Abcam, Cambridge, MA, USA } \\
\text { Catalog \#ab9071 }\end{array}$ & $\begin{array}{l}\text { Mouse IgG1 monoclonal antibody to HIV p24 - } \\
\text { mapping information non available. Selection } \\
\text { criteria: known to react with HIV-1 subtypes A to H } \\
\text { (manufacturer's communication). }\end{array}$ \\
\hline HIV-IG & $\begin{array}{l}\text { NIH AIDS Reagent Program, } \\
\text { Bethesda, MD, USA } \\
\text { Catalog } \# 3957\end{array}$ & $\begin{array}{l}\text { Human immunoglobulin. Derived from pooled } \\
\text { plasma of asymptomatic HIV-positive donors } \\
\text { selected for high titer p24 antibody. }\end{array}$ \\
\hline
\end{tabular}


Table 3: Mean concentrations of p24 measured by p24 capture Luminex using the clone 4F6 or the clone 183H12-5C and the p24 ELISA kit.Values are expressed in pg/ml.

\begin{tabular}{|l|c|c|c|c|c|}
\cline { 2 - 6 } \multicolumn{1}{c|}{} & $\frac{\mathbf{1 8 3} \text {-beads }}{\underline{n}}$ & $\frac{\text { 4F6-beads }}{\underline{\text { Luminex }}}$ & $\underline{\text { ELISA }}$ & $\frac{\text { (4F6 vs ELISA) }}{\text { p values }}$ & $\frac{\text { (4F6 vs 183) p }}{\text { values }}$ \\
\hline A - 92UG_029 & 167,480 & 428 & 50,603 & $2.70 \mathrm{E}-04$ & $3.00 \mathrm{E}-06$ \\
\hline A - 99KE_KNH1088 & 175,322 & 2,360 & 42,473 & $3.20 \mathrm{E}-04$ & $4.20 \mathrm{E}-06$ \\
\hline B - 90TH_BK132 & 77,133 & 48,228 & 10,813 & $7.60 \mathrm{E}-07$ & $7.80 \mathrm{E}-09$ \\
\hline B - 90US_873 & 73,078 & 45,370 & 11,448 & $5.50 \mathrm{E}-05$ & $1.60 \mathrm{E}-06$ \\
\hline C - 00TZ_A125 & 113,857 & 2,506 & 22,761 & $2.50 \mathrm{E}-03$ & $3.90 \mathrm{E}-06$ \\
\hline C - 93MW_965 & 197,434 & 1,986 & 69,566 & $1.90 \mathrm{E}-04$ & $6.10 \mathrm{E}-07$ \\
\hline D - 00KE_NKU3006 & 67,678 & 63,166 & 15,395 & $2.40 \mathrm{E}-05$ & $3.60 \mathrm{E}-02$ \\
\hline D - 99UG_A03349M1 & 848,124 & 487,723 & 149,826 & $9.80 \mathrm{E}-06$ & $1.00 \mathrm{E}-05$ \\
\hline CRF01_AE - 90TH_CM235 & 130,108 & 3,068 & 21,181 & $5.10 \mathrm{E}-03$ & $1.20 \mathrm{E}-07$ \\
\hline CRF01_AE - 96TH_NI 1046 & 178,372 & 4,889 & 34,077 & $1.00 \mathrm{E}-03$ & $4.70 \mathrm{E}-07$ \\
\hline CRF02_AG - 01CM_1475MV & 74,598 & 973 & 46,679 & $1.60 \mathrm{E}-03$ & $2.50 \mathrm{E}-07$ \\
\hline CRF02_AG - 98US_MSC5007 & 222,968 & 2,536 & 38,273 & $1.70 \mathrm{E}-03$ & $9.20 \mathrm{E}-06$ \\
\hline
\end{tabular}


Figure 1: Validation of the coupling reaction by flow cytometry. The different coupled microspheres (183-beads, empty circles; 39/5.4A-beads, empty squares; IG-beads, empty diamonds and 4F6-beads, empty triangles) were mixed with serial dilutions of PE-labeled detection antibody $(6.25-200 \mu \mathrm{g} / \mathrm{ml})$ and assessed by flow cytometry. The graph represents the fluorescence intensity depending on the amount of detection antibody.

Figure 2: Validation of the functionality of the capture antibodies post coupling. The capture microspheres (183-beads, empty circles; 39/5.4A-beads, empty squares; IGbeads, empty diamonds and 4F6-beads, empty triangles) were mixed with serial dilutions of purified p 24 protein, the binding was revealed by PE-labeled anti-p24 and read by Luminex. The graph represents standard curves fitted by a logistic 5P regression using Prism6.

Figure 3: p24 standard curve using the clone 183-H12-5C. The graph represents the mean fluorescence intensity of a standard curve run in quadruplicate fitted by a logistic $5 \mathrm{P}$ regression using Prism6, with $\mathrm{R}^{2}=0.9993$. The $\mathrm{CV}$ of the data is indicated below each data point..

Figure 4: p24 capture Luminex assay of the 56 isolates representing 6 HIV-1 subtypes. The graph represents the mean concentration (in $\mathrm{pg} / \mathrm{ml}$ ) of each sample ran in quadruplicate. The error bars represent the SEM (Standard Error of the Mean).

Figure 5: Inter-assay variation. p24 capture Luminex assay of the 30 isolates representing 6 HIV-1 subtypes. The graph represents the mean concentrations (in $\mathrm{pg} / \mathrm{ml}$ ) of 30 isolates run in duplicates in four idependant experiments carried out over a period of time of several months. The error bars represent the SEM.

Figure 6: Comparison of p24 concentration of the 56 HIV-1 isolates between the capture Luminex assay and the commercial ELISA kit. The concentrations are expressed in $\mathrm{pg} / \mathrm{ml}$. The empty circles represent the isolates for which the commercial ELISA kit measured higher $\mathrm{p} 24$ concentration than the Luminex capture assay.

Figure 7: p24 capture Luminex assay using anti-p24gag HIV-1 mAb clone 4F6 (full circles), clone 183-H12-5C (empty circles)and ELISA kit (empty squares). The graph represents the $\mathrm{p} 24$ titration (in $\mathrm{pg} / \mathrm{ml}$ ) of $12 \mathrm{HIV}-1$ virus isolates representing six different subtypes (A, B, C, D, CRF01_AE, CRF01_AG).

Table 1: List of the 56 isolates belonging to the 6 different HIV-1 subtypes.

Table 2: Capture antibodies references and description.

Table 3: Mean concentrations of p24 measured by p24 capture Luminex using the clone $4 \mathrm{~F} 6$ or the clone 183-H12-5C and the p24 ELISA kit. Values are expressed in $\mathrm{pg} / \mathrm{ml}$. 


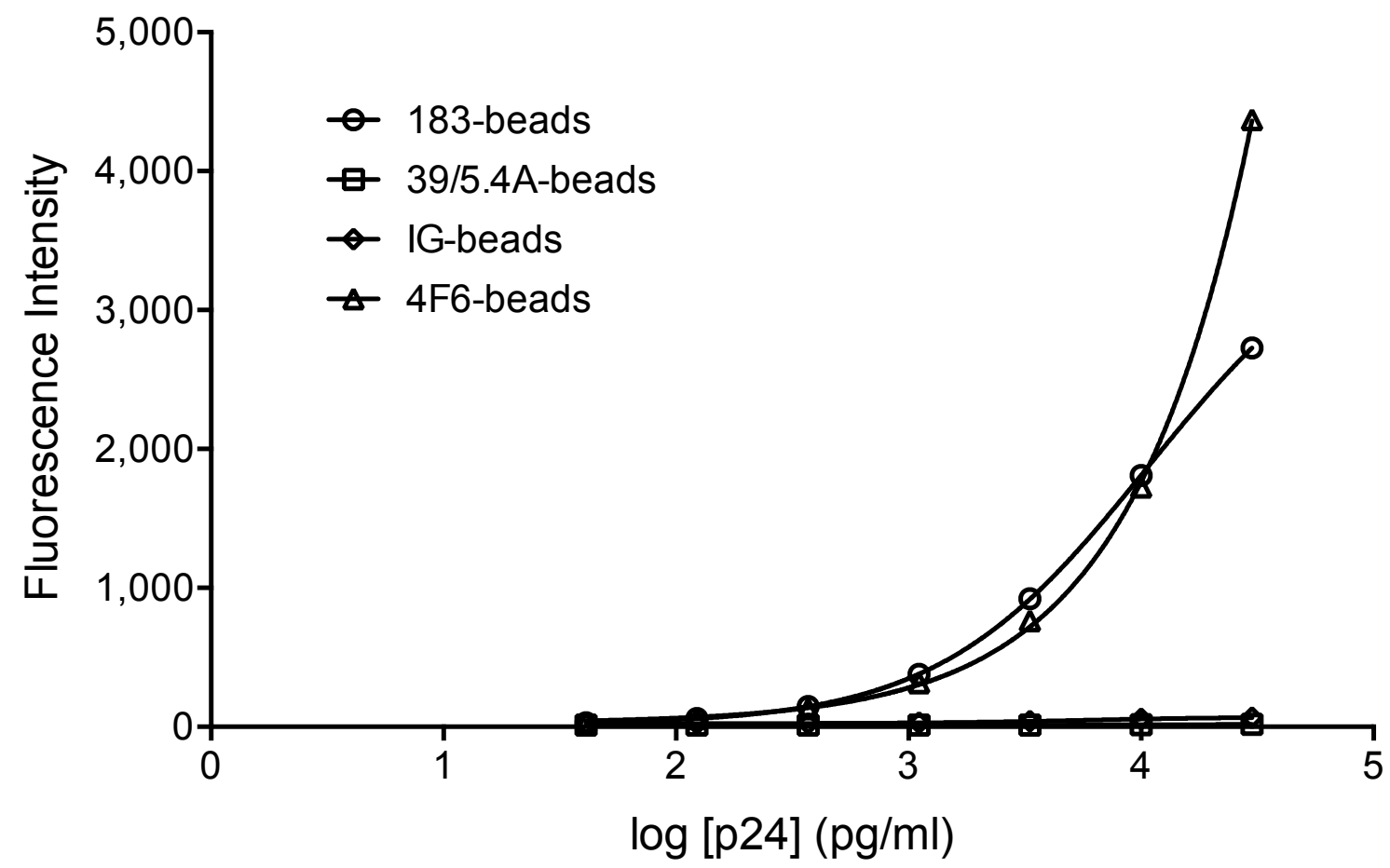

Figure 2 


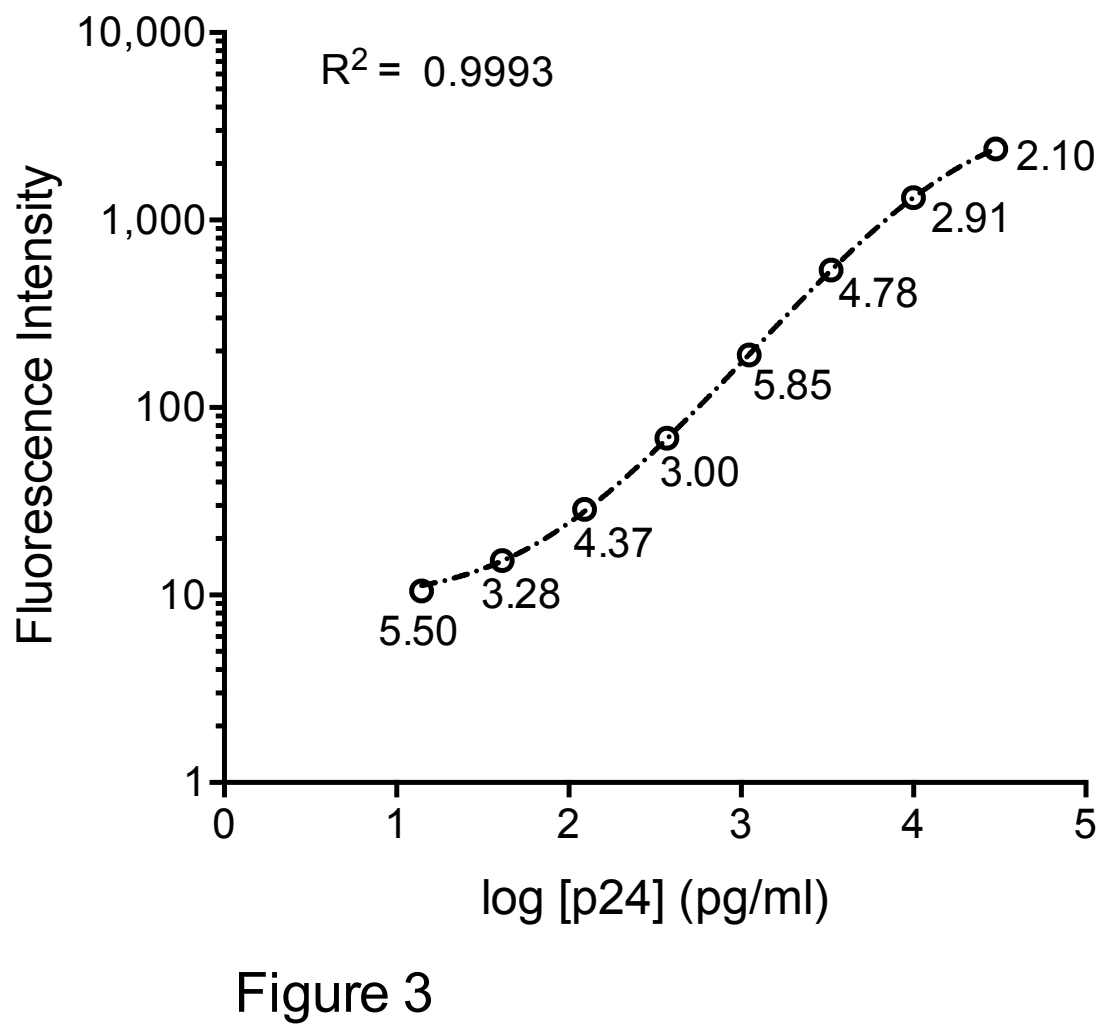




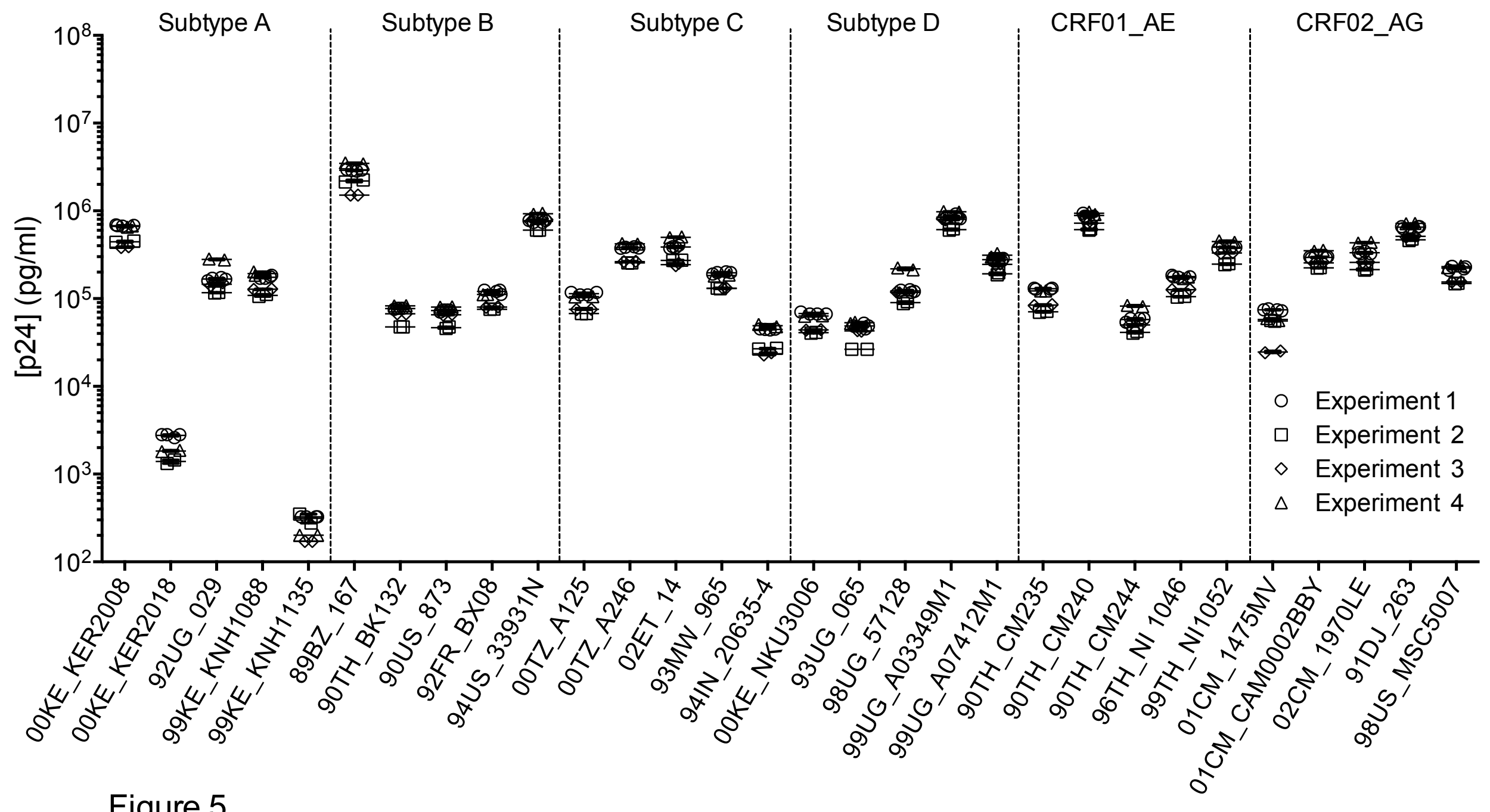

Figure 5 


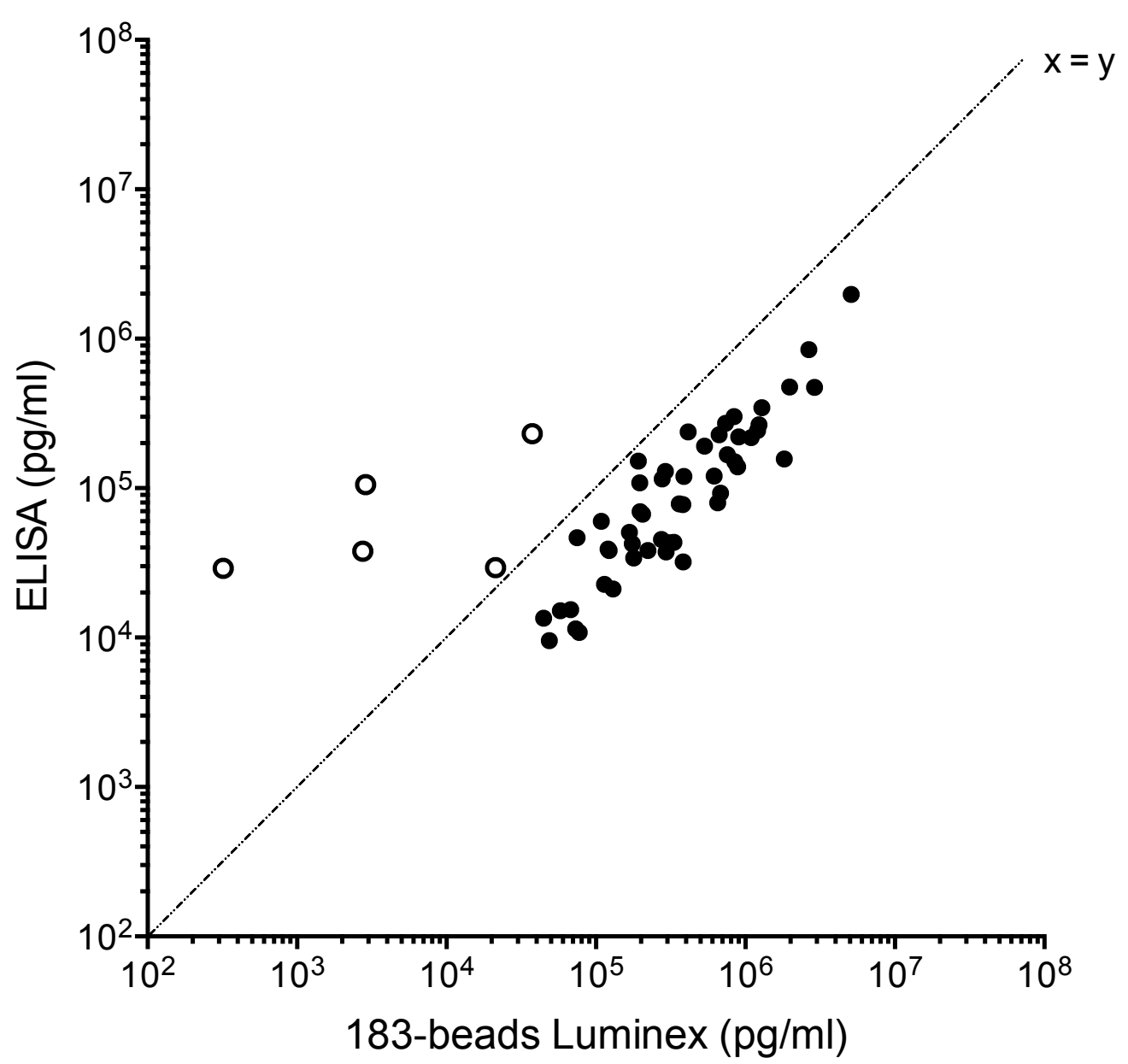

Figure 6 
